\title{
UTOPIA CAPITULADA EM CIFRA RESPONSÁVEL E OUTROS TEMAS DO CINEMA LATINO-AMERICANO HOJE
}

\section{CAPITULADA AMOUNT UTOPIA IN RESPONSIBLE AND OTHER TOPICS OF LATIN AMERICAN CINEMA TODAY}

\author{
SEBASTIÃO GUILHERME ALBANO 1 \\ MARIA ÉRICA DE OLIVEIRA LIMA 2
}

Resumo: Devido à escalada da racionalização no que tange aos processos de produção, distribuição e exibição de filmes na América Latina entre 1990 e 2011 e pela temeridade de se pensar uma teoria do cinema sem nos reportar a uma teoria do cinema como produção social, idealizou-se denominar as conseqüências do Consenso de Washington nas forças políticas e econômicas que permeiam os regimes estéticos do audiovisual da região como formadoras de uma poética da responsabilidade. No plano da representação, por exemplo, a circunstância significou uma redução do repertório retórico (figuras etc.) e parece haver instaurado (ou apenas acentuado) a dependência simbólica de audiovisualidades hegemônicas.

Palavras-chave: Audiovisual; poéticas da responsabilidade; Consenso de Washington; América Latina.

Abstract: Based on the emergence of rationalization regarding Latin American motion pictures' production, distribution, and exhibition in the last twenty-one years (1990-2011), and considering cinemas' theory as social production, we are able to evoke the Washington Consensus consequences on the movies' political, economic, and aesthetic regimes as provokers of a poetics of responsibility. On the representation

\footnotetext{
1 Professor Adjunto do Departamento de Comunicação Social e do Programa de Pós-Graduação em Estudos da Mídia (PPgEM) da UFRN. Autor do livro "A Imaginação revolucionária", Annablume, 2011. E-mail: sgac@ufrnet.br.

2 Professora Adjunta do Departamento de Comunicação Social e do Programa de Pós-Graduação em Estudos da Mídia (PPgEM) da UFRN. E-mail: mariaerica@cchla.ufrn.br.
} 
field, for instance, the circunstances have been meant as a reduction of rethoric repertory (figures etc.) and seem to have set Latin American's symbolic dependency of hegemonic audiovisualities.

Key Words: Audiovisual; Poetics of Responsibility; Washington Consensus; Latin America.

\section{Introdução}

A emergência da racionalização dos processos de produção, distribuição e exibição de filmes de cinema na América Latina a partir de 1990 e a temeridade de se pensar uma teoria do cinema sem nos reportar a uma teoria do cinema como produção social orienta em chave de consequências, a formulação das premissas deste trabalho. Primeira consequência da consignação neoliberal dos Estados nacionais da região, a entrada em crise de suas instituições e a legitimação dessa conjuntura por intermédio das Ciências Humanas e Sociais; em seguida, consequência da incorporação dos enunciados de cunho epistêmico surgidos sob a égide dos novos paradigmas em estímulos estéticos. Em ambos os casos, motivos da história recente atuam como constantes a inspirarem essas ideias. Um deles e nosso principal marco, o Consenso de Washington, por exemplo, incide nas forças políticas e econômicas que permeiam os regimes estéticos do audiovisual da região e forja o que denominamos poética da responsabilidade, termo que reitera o alcance dessa atuação ostensiva e encarna a posição mais generalizante que empregamos para tratar de levar adiante a classificação referida.

$\mathrm{Na}$ atualidade, de acordo com o regime de representação projetado, os filmes realizados na região podem facilmente ser classificados, ainda que isso enseje uma redução radical, em caudatários do chamado world cinema e, de outro lado, inscritos na lógica do cinema globalizado. Em que pese essa constatação de atrofia da imaginação, nossa intenção com a pesquisa é propiciar o estabelecimento de premissas que indiquem novas subclassificações de acordo com padrões aos que consideramos 
que remontam a agenciamentos locais dos estímulos modernos, notadamente com enunciados que pertencem ao campo semântico do termo utopia, como são os filmes ensaísticos dos novos cinemas dos anos 1960, os filmes de renovação das subjetividades próprios das chanchadas e seu afã de internacionalizar a cor local, entre outros.

Em face dessa conjuntura, nossa hipótese se orienta no sentido de que um dos sintomas dessa renovação concerne à inflexão do elenco retórico empregado nos filmes para cinema na América Latina nos últimos 25 anos. Para tanto, buscamos padrões relativos às políticas para o setor e a suas consequências no regime de representação que possam caracterizar alguma estabilidade de procedimentos estilísticos ou estéticos na produção regional, inclusive enfrentando, sem minorar, o obstáculo de hoje ser bastante difícil atribuir uma nacionalidade aos filmes, em vista da proliferação de coproduções e da suposta fragilização das instituições de legitimação do Estado nacional.

\section{Contextos: poéticas da responsabilidade, world cinema e cinema globalizado}

Como referido, devido à ascensão de um tipo de racionalidade e de racionalização plasmado nos processos de produção, distribuição e exibição de filmes para cinema na América Latina a partir de 1990, idealizou-se atribuir as consequências do Consenso de Washington nas forças políticas e econômicas que permeiam os regimes estéticos do audiovisual da região como inspiradoras de uma poética da responsabilidade. ${ }^{3}$ Se por um lado houve um incremento na confecção de produtos audiovisuais em países em que anteriormente quase inexistia a atividade em seu viés institucional, como a Guatemala e o Equador, por exemplo, no plano da representação

3 A noção de poética da responsabilidade foi desenvolvida ao longo dos últimos cinco anos. No texto "Conjuntura crítica do audiovisual latino-americano" (ALBANO, 2012) comenta-se quando seu emprego nos parece pertinente. Com efeito, o texto ora apresentado faz parte de um livro a ser publicado em 2013 como resultado de um estágio de pós-doutorado realizado na Universidad Nacional Autónoma de México (UNAM) e na University of Texas at Austin (UT). 
a circunstância significou uma redução do repertório retórico (figuras etc.) o que, paradoxalmente, parece haver acentuado o intercâmbio em paralelo com a dependência simbólica não mais de cinematografias nacionais, mas de audiovisualidades predominantes ou, se for mister o uso de um termo mais específico, audiovisualidades hegemônicas.

Parte do nosso intuito aqui é delinear categorias analíticas sumárias com o qual se possa remeter aos fenômenos do setor sem menoscabo dos paradoxos ou dos deslocamentos de sentido. Daí que, para nós, malgrado quase todos os filmes produzidos e exibidos na região a partir de 1990 se enquadrarem nos postulados da poética da responsabilidade, estabelecemos outro nível de classificação mais específico que partilha em dois modelos esses mesmos filmes. De um lado, aqueles cujos modos de produção e os regimes de representação obedecem aos ditames do world cinema (HILL \& GIBSON, 2000; CHAPMAN, 2003; NAGIB, 2005; ANDREW, 2006; MASCARELLO \& BAPTISTA, 2008) e, de outro lado, aqueles que se alinham ao cinema globalizado. Não satisfeitos com esse afunilamento já cotejado em outros exames e em outras latitudes trataremos de refinar ainda mais a observação e descrevemos, por separado, outras duas constantes do cinema na América Latina, tipologias temáticas e formais que historicamente tipificam o interesse dos cineastas e implicam tanto as características sinalizadas pelas noções anteriores (world cinema e cinema globalizado) como as condições da poética da responsabilidade. Uma corresponde ao que estipulamos como "Ideias fixas e imaginação motora: história, memória e trauma” e a segunda "Sentido comum: transensibilidades, agenciamentos e renovação do sujeito”. A primeira vinculada ao que em outros estudos atribuímos o epíteto de cinema ensaístico (CORRIGAN, 2011) ${ }^{4}$ e o outro tributário de um afã de cosmopolitismo, um cinema urbano ou com aspirações de transcendência da realidade idiomática e cultural de sua produção. Por fim, em ambos podemos vislumbrar uma potência utópica a determinar seus resultados estéticos.

4 A noção de filmes e romances ensaísticos foi descrita no livro A modernidade representada na América Latina. O romance e o filme S. Bernardo e Pedro Páramo (ALBANO, 2010). 
No primeiro caso, a expensas de não ser mais possível atribuir o estado de coisas contemporâneo como resultante de um conluio imperialista para o esquecimento coletivo, pode-se aventar a ideia da naturalização na maior parte dos autores e nas audiências regionais de uma visualidade algo pré-fabricada como ocorre em O que é isso companheiro (Bruno Barreto, 1997), Dois córregos (Carlos Reichenbach, 1999), Machuca (Andrés Wood, 2004), Los andes no creen em Diós (Antonio Eguino, 2007 ), Paisito (Ana Díez, 2008), Pachito Rex (Fabián Hofman, 2008), entre outros. Com a mesma temática e sob a mesma rubrica indicada acima, concorrem com esses filmes Que bom te ver viva, (Lúcia Murat, 1989), Los rubios (Albertina Carri, 2003), Garage Olimpo (Marco Bechis, 2006), Diário de uma busca (Flávia Castro, 2010), Sibila (Teresa Arredondo, 2011), No (Pablo Larraín, 2012), entre outros. Todavia, se na primeira série manifesta-se aquele fenômeno indicado um pouco precipitadamente por Susan Sontag quando aventava a possibilidade de uma imagem-mundo (1999) mecanizada, autonomizada e por que não também homogeneizada em suas dimensões morais e formais, na segunda parte os filmes elencados indicam a urgência de dar sentido ao passado mediante novas táticas de semiose em um lance de crítica da memória que visa a tergiversar as versões oficiais (RICHARD, 2010), tanto da história quanto do espaço, muito embora sem nostalgia pelo nacionalismo nem avidez pelos signos mais ostensivos da contemporaneidade.

Em que pese participarem do novo sistema de produção racionalizada que os anexam a uma poética da responsabilidade, o regime de representação se configura, mormente como utópico, às vezes com experiências tão introspectivas e subjetivadas que desterritorializam a história aludida, sem estar em desacordo militante. Nessas duas séries de filmes implicadas sob a rubrica de "Ideias fixas e imaginação motora: história, memória e trauma” imperam esquemas de simulacros fílmicos e epistemológicos forjados em laboratórios de Hollywood ou de Princeton acerca dos eventos das ditaduras e demais mazelas políticas da América Latina. Isto é, seu regime de representação não se refere à cronotopia referencial e apresenta uma idealização 
pré-fabricada pelo Ocidente moderno (uma vez que etimologicamente utopia quer dizer lugar nenhum ou um não-lugar, independentemente da carga depreciativa atribuída por Marx e Engels aos socialistas utópicos anglófonos e francófonos do Dezoito e do Dezenove, e alheio também à escalda de uma acepção relativa à esperança, à valoração e ao que Karl Mannheim cria ser um projeto subversivo, quando não antípoda ao menos precedente da ideologia) (1976).

$\mathrm{Na}$ outra categorização geral, "Sentido comum: transensibilidades e renovação do sujeito” alinharam filmes que desde os anos 1980 se habilitam para representar ou, em chave de simulacro, apresentar os traços da utopia pós-moderna de renovação do sujeito, uma vez que campeiam motivos do multiculturalismo, da globalização, do novo politicamente correto (acrescido dos valores da esquerda puxados pela direita). Os exemplos iniciais foram realizados ainda sob os limites institucionais do Estado autoritário ou lidando com seus resíduos sem esboçar alusão à circunstância, como Cidade oculta (Chico Botelho, 1986), A dama do cine Shanghai (Guilherme de Almeida Prado, 1988), Hombre mirando al Sudeste (Eliseo Subiela, 1986), Rapado (Martin Rejtman, 1991), Lola (Maria Novaro, 1989), Cronos (Guillermo del Toro, 1993).

Mas esse quadro consolida-se a partir dos anos 2000, com a ascensão de um quadro expressivo atravessado majoritariamente por signos cuja remissão não é mais caudatária da história dos discursos representativos como a literatura popular ou o cinema, ou mesmo tão somente de um recorte dos simulacros promovidos pelos próprios meios, mas invoca uma nova materialização dos signos de referências espaciais e temporais filtrada pelas soluções auspiciadas pela cultura pop, como em Bolivia (Israel Adrián Caetano, 2001), Los guantes mágicos (Martín Rejtman, 2003), Batalla en el cielo (Carlos Reygardas, 2004), Whisky (Pablo Stoll e Juan Pablo Rebella, 2004), Madeinusa (Claudia Llosa, 2005), Las hamaca paraguaya (Paz Encina, 2006), La mujer sin cabeza (Lucrecia Martel, 2008), Año bisiesto (Michael Rowe, 2010), Viajo porque preciso volto porque te amo (Marcelo Gomez e Karin 
Aïnuz, 2009), Os famosos e os duendes da morte (Esmir Filho, 2009), La marimbas del infierno ( Julio Hernández Cordón, 2010), Alegria (Felipe Bragança e Marina Meliande, 2010), A febre do rato (Cláudio Assis, 2011), El último Elvis (Armando Bo, 2012), entre outros. Isto é, ainda sob as rubricas de "Ideias fixas e imaginação motora: história, memória e trauma" ou de "Sentido comum: transensibilidades, agenciamentos e renovação do sujeito” em alguns deles há um regime de representação mais orientado pelas lógicas do cinema global e outro pela do world cinema, mas em qualquer circunstância os filmes estão condicionados aos parâmetros da poética da responsabilidade.

Uma vez delineadas as últimas noções classificatórias, nota-se desde já uma capitulação da ideia de utopia atribuída até então aos filmes dos Nuevos Cines Latinoamericanos do decênio de 1960 e nos resta definir as noções mais gerais prometidas ao início do texto. Poéticas da responsabilidade, por exemplo, é uma corruptela provinda de conceitos cunhados por Max Weber e inspiradas na sua teoria sobre a atuação dos líderes em uma sociedade complexa. Não é excessivo recordar que as categorias de ética da responsabilidade e ética da convicção (WEBER, 1982) concernem a um agente político que deveria ser levado a tomar decisões motivadas, no caso da segunda hipótese, por uma ética relativa aos valores ou convicções e, no caso da primeira, mirando a eficácia e eficiência dos meios para alcançar as finalidades, sempre vinculados a circunstâncias e interesses provisórios.

Adaptamos o sentido de ética da responsabilidade com algum reparo a fim de sustentar nossa tese a respeito da impressão mais consistente que se tem dos resultados da racionalização neoliberal da atividade cinematográfica contemporânea na América Latina a partir de 1990, cujo resultado foi o conceito de poética da responsabilidade, tanta a ponderação mercadológica que os atores envolvidos no processo de concepção de um filme adotam e tamanho o aspecto burocrático de sua concreção como filme. Se esses dados estão demasiado explícitos em, por exemplo, Miroslava (Alejandro Pelayo, 1993), Sexo, pudor y lágrimas (Antonio Serrano, 1999), 


\section{míDiA

Amores perros (Alejandro González Iñárritu, 2001), Nueve reynas (Fabián Bielinky, 2001), Vereda tropical, (Javier Torre, 2004), Se eu fosse você (Daniel Filho, 2006), Divã (José Alvarenga Filho, 2009), como referido, está presente em quase todos os filmes que produzidos na região e que chegaram a nossas telas de cinema.

Grosso modo, entende-se por world cinema, ao menos em nosso caso, aqueles filmes que exercem um método de produção, distribuição e exibição diverso aos de Hollywood e, ademais, participam de um padrão de mimese e de verossimilhança grato ao circuito dos festivais internacionais. Malgrado seu emprego na pesquisa, cumpre mencionar que seus formuladores (HILL \& GIBSON, 2000; CHAPMAN, 2003; NAGIB, 2005; ANDREW, 2006; MASCARELLO \& BAPTISTA, 2008, entre outros), em favor de uma astúcia pós-moderna, estabelecem uma condição de igualdade ontológica entre os filmes de Hollywood e os filmes do world cinema, posição que chamaríamos de pós-histórica ou de a-histórica, uma vez que se inscreve na lógica dos enunciados dos Estudos Culturais, dos Estudos Pós-Coloniais, mas preferem não politizar explicitamente a situação hegemônica de Hollywood e sugerem um esquema alternativo que, não obstante sua aparência, acreditamos não se caracterizar por ser tão alternativo assim. Enquadram-se aí Hotel Atlântico (Suzana Amaral, 2009), Del amor y otros demonios (Hilda Hidalgo, 2009), Impulso (Mateo Herrera, 2009). No caso do termo cinema globalizado, adotamos a ideia de Tamara Falicov (2000) quando argumenta que muitos dos filmes argentinos do período estudado por nós são em verdade filmes de Hollywood falados em castelhano. Ampliamos o horizonte e atribuímos o mesmo raciocínio a outras tradições nacionais como nos filmes En el tiempo de las mariposas (Mariano Barroso, 2001), Segurança nacional (Roberto Carminatti, 2004), Dos Hermanos (Daniel Burman, 2010) e Traspatio (Carlos Carrera, 2009).

Isso posto, resta comentar que essa multiplicidade de perspectivas arroladas aqui promove a indagação acerca das modificações operadas na instância da representação (cronotopia, figuras, linguagem e técnica) em filmes latino-americanos 


\section{míDiA

realizados e exibidos nos cinemas da região a partir da adoção das medidas políticas e econômicas preconizadas pelo Consenso de Washington, cujo marco no setor foi a extinção da EMBRAFILME em 1990 e a reestruturação do IMCINE, no México, e do INCAA, na Argentina, países em que a soma dos filmes exibidos orçava 89\% do total produzido na América Latina e Caribe até 2000 (GETINO, 1998, p. 50). Essa renovação corresponde aos resultados de um aparelho de argumentações de procedência variada (epistêmicas, doxais etc., relacionadas principalmente com a emergência do neoliberalismo) na concretização de uma nova modalidade de realização orientada para a busca de coproduções e o incremento no processo de internacionalização do setor, muito embora os Estados permaneçam como incentivadores na produção, isentando-se apenas da distribuição e da exibição. Esse lance algo sutil da globalização, cujas consequências retóricas e estéticas são patentes, é auspiciado por instituições politicamente corretas como o fundo Ibermedia e por incentivos como os do Hubert Bals Fund do Festival de Rotterdam ou as bolsas do Sundance Festival ou o apoio do World Cinema Fund, reserva do governo alemão veiculado pelo Festival de Berlin que financia filmes produzidos nos países em desenvolvimento.

Todavia, atente-se ainda para o dado de que esses mecanismos represam as energias criativas em direção às cláusulas dos seus estatutos e se em verdade propiciam uma proliferação de produção no continente, incluindo entre os produtores, como referido, países sem tradição no setor, endereçam as marcas discursivas para uma imaginação exótica. Prova disso está em que se o fundo berlinense apenas enfatiza a circunstância de país em desenvolvimento como prerrogativa do apoio, entre as convocatórias do Hubert Bals Fund destaca-se o vinculo entre a concessão da bolsa e a característica não ocidental do filme ou do país do diretor. Nos últimos anos, entre os brasileiros, A casa de Alice (Chico Teixeira, 2006), Deserto Feliz, (Paulo Caldas, 2007) e A festa da menina morta (Matheus Nachtergaele, 2007) foram contemplados com o subsídio e, subtextualmente, seus produtores e diretores não se importaram em 


\section{míDiA

rechaçar, ao menos pro forma, sua constatada tradição ocidental. Entre os argentinos agraciados com o incentivo estão Dos Hermanos (Daniel Burman, 2010) e Carancho (Pablo Trapero, 2010), estranhamente filmes que retratam situações urbanas e com diegese isenta de sinais exóticos.

Tratamos de lançar luz sobre esses novos e paradoxais parâmetros estéticos e sociopolíticos mediante um vocabulário atualizado que remeta a aspectos da tradição fílmica (cinematográfica), mas norteie o traçado de linhas de pensamento acerca do processo de transformação do setor ocorrido a partir do Consenso de Washington (YÚDICE, 2002). Para tanto, a terminologia convoca fenômenos que estão além das periodizações históricas cristalizadas e, ademais, tangenciam a complexidade do campo do audiovisual na contemporaneidade. Noções como poética da responsabilidade, imagens de consenso, world cinema, cinema globalizado, cinema transnacional, tradição iconográfica, crise da linguagem e da mimese, utopia, distopia, heterotopia etc. devem ser trazidas à baila e filtradas por sua atuação no regime de representação (mimese, projeção, métodos de formação de imagens e seus critérios de apresentação e valoração estética e moral etc.). Com a habitual naturalização de projetos progressistas pelos enunciados das instituições mais conservadoras, convém uma recapitulação do vocabulário que tangencia os esforços mais autênticos de nomeação das diferenças, das subalternidades, das discrepâncias materiais e das transformações dos discursos utópicos.

\section{Comentários: novos pressupostos para antigas subordinações}

A ideia de fundo é, então, relativizar certezas politicamente corretas a respeito de uma reforma no paradigma das relações internacionais lato sensu em que se esboça uma condição de igualdade entre partes cujas relações foram historicamente desequilibradas, mais ainda no âmbito da cultura. Para tanto, insistimos em que, não obstante viceje a ideologia de um mundo multipolar, ainda à semelhança do sistema de 


\section{míDiA

substituição de importações de décadas atrás, as políticas para o setor e mesmo a imaginação projetada pelo cinema produzido na América Latina mantiveram e mantém uma visão algo reflexiva em relação às cinematografias de certas regiões, notadamente no tocante à dramaturgia e às séries iconográficas selecionadas para o modelo de mundo plasmado nos filmes. Mas a despeito de sua recalcada aparência de subalternação, ao se tratar de discursos de natureza dúbia (poética e comunicativa estética e industrial) a situação reveste-se de um matiz de paradoxo. Tanto mais quando nos propomos a examinar e comentar séries de filmes a partir de sua inscrição geopolítica mediante um crivo ao que denominamos estético, uma combinação em declínio.

Notadamente depois da adoção do Consenso de Washington a circunstância não escapou a ser assimilada de maneira mecânica pelos saberes acadêmicos resultando na entrada em cena de novos aparatos conceituais franqueados pelas teorias do cinema nos últimos 30 anos (STAM, 2000; RAMOS, 2005; NAGIB, 2005) quase que para azeitar a máquina explicativa dos Estudos Culturais que talvez desse sinal de já estar um pouco oxidada. Como dissemos, países sem tradição audiovisual institucionalizada como a Costa Rica (Agua fria del mar, Paz Fábrega, 2009) e o Equador (Pescador, Sebastián Cordero, 2011) veem seus filmes ser exibidos e premiados em festivais internacionais ao mesmo tempo em que se radicaliza uma espécie de sujeição à qual estão expostas as condições materiais e, quase como consequência, a verossimilhança fílmica na região. Cresce o assombro quando se lhe confere invariavelmente o predicado de múltipla a uma cinematografia que, mesmo em seu amplo conjunto (SHAW, 2007), está em tudo limitada, malgrado se saiba que à primeira vista não haja equívoco em afirmar o contrário.

Inclusive se nos munirmos dos argumentos acerca de que a América Latina tem uma larga tradição visual tanto de matriz autóctone e cristã como advindo da relação dessas fontes com os sinais da contemporaneidade, não demoramos a concluir que, na medida do possível, a genealogia das imagens e dos aspectos relativos aos estatutos 


\section{míDiA

formais do cinema está para além dessa história meio determinada geograficamente, e se constituiu em um sistema com características semi-autônomas cuja descrição implica percorrer caminhos à primeira vista díspares. Tencionamos, de alguma maneira, comparar a complexidade e definir constantes nas formações discursivas atuais, mas sabemos que talvez cheguemos apenas a levantar alguns pontos que possam ilustrar nossa ideia da conjuntura da produção de cinema no continente nos últimos 25 anos, com ênfase em suas interseções culturais, civilizadoras e em sua fatura estética.

Muitas das impressões inscritas acima permeiam os estudos dos cientistas sociais há tempos na América Latina e fora dela, mas, agora parecem ensejar uma reforma do instrumental teórico que opere em uma dimensão cada vez mais abstrata e combinatória para tratar de dar conta de seus propósitos, como esboçamos anteriormente. Portanto, não se devem descurar em princípio os resultados obtidos por equipes de diretores, fotógrafos, montadores etc., de regiões que passaram por processo civilizatório com alguma semelhança ao da América Latina e o rearticularam discursivamente de outro modo, especialmente quando relativizam a questão nacional de superfície, como ocorreu com toda uma geração de cineastas do sudeste asiático, Coréia e territórios da China não continental, cujo mote de representação, ainda que cronotópico seja permeado pelo que Silviano Santiago denomina de cosmopolitismo do pobre (2004). Colonizados por diversos países europeus e depois de 1945 debruçados sobre o dilema de narrar a condição pós-colonial no horizonte da Guerra Fria, um assunto que em sua feição teórica foi muito desenvolvido pelos escritores do Caribe, do Oriente Médio, da Índia e do Paquistão, aqueles extremo-orientais talvez tenham estado mais à vontade para comentar o contexto pós-colonial em chave estética, vide o boom de seus artistas, de escritores a performáticos, devido mesmo a especificidades culturais acrescidas de sua peculiar trajetória de inserção capitalista e dos movimentos migratórios do qual participaram e ainda participam. 
Por seu turno, cumpre recordar que as instâncias que ao mesmo tempo em que criam tendem a avalizar essas dimensões da expressão participam do chamado concerto internacional e dentre suas atribuições está a valoração das ideias, práticas, agenciamentos e conteúdos sociais em geral e das artes em particular. Se eventualmente nos assombram noções como geopolítica cultural e divisão internacional do trabalho, atualíssimas conquanto cada vez mais esvaziadas como articuladora dos sentidos, se contemplarmos os relatos das rusgas entre departamentos de humanidades e especialmente de literatura na academia ocidental nos últimos cinquenta anos, conferimos-lhe um novo crédito. E se percebermos que os vários membros do que se convencionou denominar a diáspora pós-colonial encontraram um locus de onde falar ao mundo, tal como Aimé Césaire, Frantz Fanon, Stuart Hall, Edward Said (KENWAY \& FAHEY, 2009; SPIVAK, 2010), que não propriamente seu lugar de origem, nascimento ou criação, tangenciamos a complexidade da globalização, da mundialização e da cosmopolitização. Acima de tudo porque nos interessa, lançamos nova mirada à conjuntura do audiovisual na América Latina para nos instalarmos de pronto na situação já referida como paradoxal. Algo parece haver mudado na relação de forças políticas e epistemológicas que moldam nossa percepção da tradição cinematográfica ao mesmo tempo em que algo parece estar onde sempre esteve.

Recentemente houve uma diversificação e internacionalização da disponibilidade técnica e de financiamento na área do audiovisual, expedientes que muitos Estados latino-americanos não puderam encarregar-se de administrar devido a uma falência logística logo após alguns decênios de guerras civis, ditaduras conservadoras e ofensivas neoliberais predatórias, mas essa diversificação e internacionalização deram-se em concorrência com um enquadramento ético e estético. Esse, à diferença dos países e enclaves do sudeste asiático recém-colonizados por ingleses e franceses, mas sem a adoção plena de seus idiomas, reportou-se tão somente a um campo de influências norte-americano que doutrinou severamente os 


\section{míDiA

territórios mais débeis do continente (América Central, parte do Caribe e do norte da América do Sul) e pavimentou, com seu agressivo modelo de distribuição e exibição, a formação dos hoje realizadores de filmes na fruição de um imaginário propagado pela ostensiva indústria cultural internacional, capitaneada pelas lógicas de Hollywood ainda que, certamente, em muito hibridizadas e, como referido, dialogando com as epistemes que prometem dar voz aos subalternos. Dentre outras coisas, germinou nesse estado de coisas uma poética que no campo do fabrico de imagens e ainda mais imagens para cinema ensejam proporcionar arranjos inesperados. Se às vezes trabalhamos com a metáfora da substituição de importações no caso da recente retomada da produção de países como a Argentina, o Brasil e o México, se mudarmos o foco para o cinema da América Central e o Caribe o tropo também deve ser outro, já que ali ocorre uma produção de cunho institucional incipiente que repercute na forja de um regime de representação que leva a que participe, quase que por antonomásia, dos novos esquemas dos novos players internacionais, isto é, aqueles que se erigem como uma alternativa viável para o sistema dos estúdios de Hollywood e financiam filmes do mundo para serem exibidos principalmente em festivais, que se proliferaram exponencialmente.

De qualquer maneira, qual experiência nos suscita, ou mesmo, o que nos demonstra uma película como a guatemalteca Las marimbas del infierno (Julio Hernández Cordón, 2010)? Mesmo que ainda não possamos ou não queiramos responder essa questão, se não mais nos choca ver mesmo no cinema de ficção a discrepância cultural relativa a uma banda de heavy-metal formada por quichés guatemaltecos, país cujos últimos intentos de constituir um projeto mais ou menos autônomo de sociedade foram violentamente censurados com o apoio de instituições do Estado norte-americano, se deve a que o registro em que foi representada a diegese esteja em código consensual, sobretudo no que tange ao que em retórica se chamam as peripécias. No filme, a despeito de uma série de percalços de ordem econômica, os rapazes da banda devem conseguir uma marimba para compor, hibridamente, seu 


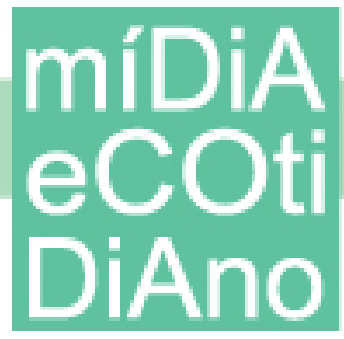

grupo de rock. Sob o controle do realismo naturalista o enredo se torna uma alegoria dos protocolos da cosmopolitização apregoada pelas Ciências Sociais pós-modernas. Com efeito, uma norma estilística seguida pelo filme concerne ao estabelecido por certo realismo naturalista que medrou com o ressurgimento ou mesmo em alguns casos o surgimento do cinema asiático, do tipo da Nouvelle Vague de Hong Kong e de Taiwan, entre muitos outros, com acentuado poder de ingerência e sedução sobre as demais cinematografias, digamos, descentradas, vejam-se os casos de Madeinusa (Claudia Losa, 2005) e La hamaca paraguaya (Paz Encina, 2006), entre muitos outros.

Essa marca genérica (o realismo naturalista) proposta em muitas produções daquela região (salvo exceções não triviais: Wong Kar-Wai, Apichtpong Weerasethakul, Takashi Miiki) parece haver sido a chave para que as referencialidades não ocidentais mais ostensivas fossem observadas para além do exótico. Por certo, essa figura perdeu muito de sua nota de interesse no mundo pós-colonial, urbanizado, pós-moderno e cosmopolita (o mundo não mais mediterrânico ou atlântico, mas acrescido das correntes comerciais do oceano Pacífico), entre outras séries de enunciados que ascenderam logo após a Segunda Guerra com o cenário de provincização da Europa erigido pelos pensadores da diáspora com base de trabalho nos Estados Unidos (CHAKRABARTY, 2000). Durante o período do Cinema Novo, por exemplo, como atestam Ismail Xavier (1993) e Robert Stam (2005), houve instantes em que certa ordem discursiva foi recriada em cifras dialógicas que deixaram um travo libertário, especialmente em filmes como Macunaíma (Joaquim Pedro de Andrade, 1969) e El topo (Alejandro Jodorowsky, 1970). Mas a imbricação de interesse antropológico com pulsão poética típica de algumas produções, sobretudo brasileiras, entre 1960 e 1975, foi naturalizada pelos discursos teóricos e pela consequente prática cinematográfica e tornou-se uma norma quase conservadora.

O feixe de dispositivos estilísticos que são ativados pelos modos de figuração do realismo naturalista possibilitaram a solução de dois problemas, hoje imperativos, por certo atribuíveis também ao Cinema Novo e ao Nuevo Cine 


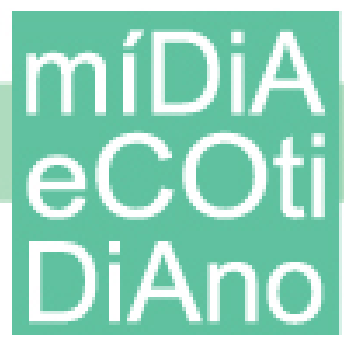

Latinoamericano das imediações de 1960, mas reencarnados no que os especialistas denominam de accented cinema (NAFICY, 2001) ou de world cinema (ainda que pareçam reverberar a hipótese do Terceiro Cinema do grupo Liberación argentino, suas semelhanças são bem superficiais). De um lado, representar as interações civilizatórias de modo discreto, sem aparatos de interpretação dos fundamentos culturais, sem o típico ensaísmo que acometia parte dos discursos das artes na América Latina e forçava dentro do campo de visão (o quadro) os signos que só tinham sentido fora do campo. De outro lado, solucionar o problema da invisibilidade das comunidades subalternas da sociedade contemporânea e cumprir com o ditame de que todo mundo, todos os tipos humanos, têm o direito e a necessidade de realizar produtos audiovisuais que deem conta de certas práticas, de certas comunidades, das patrias chicas e seus slangs ou calós, cumprindo o acordo tácito da sociedade da informação de que todos têm o direito e devem ser visíveis (SIBILIA, 2010). Mas esses ditames tendem a debilitar as forças criadoras, e se o realismo naturalista logra, no plano estético, manobrar os sentidos de modo algo inesperado e produtivo e realiza a dialética entre o que está dentro e fora do campo, em geral outras regularidades estilísticas do cinema contemporâneo na América Latina são mais problemáticas.

Boa parte das imagens cinematográficas que conhecemos corresponde mesmo à ordem da reelaboração da iconografia e da representação figural (e talvez menos do que o devido à plástica e à invenção), cuja necessária referencialidade aderese, sobretudo, à história da representação no próprio cinema ou em discursos correlatos, como o romance e as epistemes (história, sociologia etc.). Parece ocorrer também um movimento de intertextualidade ou de geração de simulacros atribuível, provisoriamente e sem idealismo ou simpatia positivista, ao que se supõe sejam a sobrevivência de certas formas ou motivos do passado em obras contemporâneas, ou ainda sua recorrência em simultaneidade em expressões de culturas destoantes (ativando o movimento que Aby Warburg descreve como uma espécie de efeito Mnemosyne, 2002). Nossa aposta neste texto se orienta pela existência de um projeto 


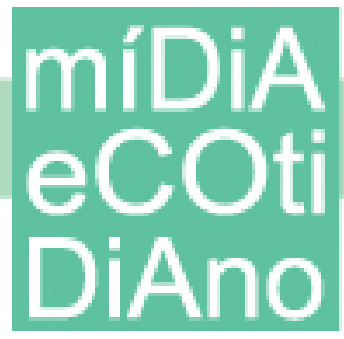

mais ou menos oculto de busca por consensos que opera em uma relação próxima à construção de certo ethos ou de certo pathos, em suma, de uma sensibilidade e uma imaginação que propicie a comunicação e, por conseguinte, a formação das estruturas que levam à subordinação. Em que pese imagens e motivos historicamente vinculados ao lirismo ou mesmo à subversão dos sentidos sejam recorrentes em filmes contemporâneos (Orfeu, Cacá Diegues, 1999, baseado em Orfeu Negro, Marcel Camus, 1959, adaptado da peça Orfeu da Conceição, de Vinícius de Moraes, inspirado na ópera Orfeu e Eurídice de Christoph Willibald Gluck, 1762, sugerido pelas histórias clássicas de Orfeu e Eurídice; ou Mentira piedosas, Diego Sabanés, 2009, relativo ao conto de Julio Cortázar, La salud de los enfermos), essa revisões resultam inócuas no contexto do sistema de produção, reprodução e recepção contemporâneo.

Muito embora na superfície da imagem em movimento, ainda nas mais cerradas e recalcitrantes, comumente divisem-se virtualidades de sentido e de modos de afetividade, por exemplo, a predominância global e já centenária de um formato de cinema que projeta um tipo de existência ou um estar no mundo determinado nunca foi e não poderia ser escamoteada pelas disciplinas acadêmicas contemporâneas (Estudos Culturais, Pós-Colonialismo, Estudos Feministas, Estudos Subalternos, Queer Studies etc.), produtoras de itinerários investigativos em que os agenciamentos e outras questões de consolidação de identidade, sobretudo identidade étnica, sexual, cultural e de classe filtram a observação e arquitetam verdades.

\section{Reflexões imperfeitas com finalização incompleta}

Nesse cenário, entretanto, o cinema da América Latina, salvo exceções (talvez Lucrecia Martel, Carlos Reygadas, Alejandro González Iñárritu sejam os nomes mais conhecidos, muito embora estejam no projeto também Claudia Llosa, Paz Encina, Martín Rejtman, Juan Hernández Cordón, Pablo Larraín e Cláudio Assis), ainda não logra delinear singularidades autorais e tampouco vocalizar subjetividades 


\section{míDiA

coletivas ou agenciamentos, ao menos diante das instituições que ajuízam o gosto contemporâneo. No primeiro caso, pouquíssimos cineastas alcançaram até agora realizar um conjunto de obra substancial, a despeito das promessas. No terreno estilístico, ainda com alguma variedade de superfície, em geral se mantém uma propensão ao retrato de efemérides históricas conforme métodos anacrônicos de representação ou mesmo de acordo com um uso superficial da genealogia narrativa e iconográfica (Entre Pancho Villa y una mujer desnuda, Sabina Berman e Isabel Tardán, 1995, O que é isso companheiro?, Bruno Barreto, 1997, Machuca, Andrés Wood, 2004), e à duvidosa demonstração de uma problemática urbana com afã sociológico (La vendedora de rosas, Víctor Gaviria, 1998, De la calle, Gerardo Tort, 2001, Antônia, Tata Amaral, 2006, Cinco vezes favela, Rodrigo Felha, Cacau Amaral, Luciana Bezerra, Cadu Barcellos, Luciano Vidigal, Manaira Carneiro e Wavá Morais, 2009). Sem exceção, esses filmes inserem-se nos métodos do cinema globalizado e todos seguem, portanto, o pendor ensaístico que cultiva a interpretação da realidade histórica, em muitas ocasiões, construída pelos discursos acadêmicos, como se apenas nesse âmbito se encerrasse um saber válido, uma cognição passível de ser expressada, como se a ficcionalização ou a imaginação não detivessem suas próprias vocações intelectivas por intermédio de estímulos menos permeados pela racionalidade à qual estamos acostumados.

Há ainda a modalidade de filmes que se remetem aos ditames do world cinema que, muito embora apresentem um respiro retórico tímido, como referido conseguem aparentar alguma ruptura com a codificação ostensiva. A obra de Lucrecia Martel, Martin Rejtman, Carlos Sorín, Karim Aïnouz, Kleber Mendonça Filho, Sérgio Machado, Paz Encina, Mauricio Rial Banti, Claudia Llosa, entre outros, afiança a inquietação pela expressão de uma subjetividade renovada. Agora bem, em qualquer dos casos referidos, os grandes enunciados das Ciências Sociais e Humanas que rondam o espaço público contemporâneo são mais que alusões nos filmes mencionados e muito mais que mero horizonte de opções. São eles mesmos formados 


\section{míDiA

e formadores de uma racionalidade que impinge ao audiovisual, por si só um modo de conhecimento, uma perspectiva determinada, heteronômica e promotora também da poética da responsabilidade.

Quando se unem os planos sincrônicos e diacrônicos acresce-se a tais convicções que configuram uma estética negativa as quase inevitáveis circunstâncias de dependência, especialmente no que concerne à distribuição e à exibição, tópicos ordinários no debate acerca dos problemas do cinema latino-americano e de outras regiões até bem pouco tempo e que prossegue. Um corolário superficial dessa acareação de perspectivas corresponde ao fato de que se até 1990 os motivos da nossa subordinação no campo fílmico eram mais ou menos explícitos, a partir do momento em que houve o que se convencionou chamar de retomada no Brasil e o surgimento do Nuevo Cine Argentino e do Nuevo Cine Mexicano, afora o reinício ou início da atividade audiovisual institucionalizada em países como o Chile, o Uruguai, o Peru, o Equador, a Costa Rica, a Guatemala etc., aqueles foram suplantados por causas um pouco mais discretas que se reportam às esferas da atuação ideológica, patente nas novas diretrizes da ordem mundial pós-URSS e dos lineamentos do Consenso de Washington, que ainda reverberam nas questões da cultura em geral e das indústrias culturais em particular (YÚDICE, 2002, p. 20).

Por seu turno, uma conclusão menos peremptória e que, por conseguinte, relativiza, no tocante às constantes formais e de conteúdo, o que nomeamos de estética negativa, surge com a suposição de que a reflexão de parte dos realizadores acerca dos tópicos referidos pode haver sido obstaculizada pelas normas advindas da institucionalização liberal dos anos 1990, ao confinar o acesso à recepção (situação incipiente em que se despertam futuros autores) e à produção aos dispositivos de mercado, operando em favor dos mais competitivos e erigindo o formato norteamericano como paradigma, o cinema por antonomásia. Se por um lado, o escritor e crítico argentino Alan Pauls acredita que hoje no cinema regional "forma y producción son el mismo problema” (AMATRIAÍN, 2009, p. 38), remoça, em uma conjuntura 


\section{míDiA

diversa e em nota crítica, as consignas de seu patrício Fernando Solanas (El tercer cine), do cubano Julio García Espinosa (Por un cine imperfecto) e de Glauber Rocha (Estética da fome) que na década de 1960 promulgavam uma vinculação do cinema latino-americano às condições sociais da região. Visavam a transcender a metáfora de substituição de importações e criar um sistema consoante às necessidades locais. Naquele então, orçamentos baixos, tomadas externas, luz natural ou quase, câmera na mão, certo expressionismo ou naturalismo barroco, continuidade relaxada, montagem cubista, temas com lastro social ou de cunho histórico ou rural, muitas vezes observados como grandes signos da verdadeira soberania nacional nas telas, entre alguns outros, eram as rubricas do cinema regional.

Hoje, condicionados a esquemas de coprodução e internacionalização, o regime mimético, de representação, e seus enunciados, estão dispostos por difusos sujeitos da enunciação, donde a pergunta acerca de quem fala nos filmes parecer tanto mais relevante do que a questão acerca de o que se fala. Cremos, inclusive, que se deve deslocar a preocupação estruturalista a respeito do como se fala, para a de quem é o sujeito da enunciação de boa parte dos filmes latino-americanos contemporâneos, de cunho pós-estruturalista. Ou melhor, talvez a questão mais pertinente seja se em verdade há um sujeito ou se são os distintos agenciamentos formados no fluxo dos interesses, dos desejos e do poder que organizam as enunciações em filmes falados em espanhol, português (ou guarani, aymara, mapuche etc.) e produzidos e distribuídos na região no período mencionado, mas tão radicalmente desterritorializados e reterritorializados, que de um lance não só problematizam a questão dos sujeitos da enunciação como capitulam a noção de utopia. Nesse último caso, retiram-lhe o lastro de esperança e luta e simplesmente lhe restituem o sentido de não lugar, lugar nenhum, o que no caso do cinema não seria um problema não fosse esse outro argumento falacioso. Isso porque o lugar representado não é tão somente uma cosa mentale, como houvesse dito Leonardo da Vinci, mas um lugar diegético histórico, cujas coordenadas 
são símbolos que aludem a uma civilização que, se não está em prejuízo, medra à revelia de outras.

\section{Referências}

ALBANO, Sebastião Guilherme. A modernidade representada na América Latina. Os romances e os filmes S. Bernardo e Pedro Páramo. Natal: EDUFRN, 2010.

"Conjuntura crítica do audiovisual latinoamericano”. In: ALBANO, Sebastião Guilherme; LIMA, Maria Érica de Oliveira; REYES, Aurelio de los. Cronotopias. A renovação do audiovisual Ibero-Americano. Natal: EDUFRN, 2012.

AMATRIAÍN. Ignacio (coord.). Una década de Nuevo Cine Argentino. Buenos Aires: Ciccus, 2009.

Anuario estadístico IMCINE. México: IMCINE, 2010.

BADIOU, Alain. Compendio de metapolítica. Trad. Juan Manuel Spinelli. Buenos

Aires: Prometeo, 2009.

BONFIL, Judith (coord.). Producciones/Productions 2007-2009. México: Consejo Nacional para la Cultura y las Artes, 2009.

CANCLINI, Néstor García; MONETA, Carlos (coords.). Las industrias culturales en la integración latinoamericana. Cidade do México/Caracas: Grijalbo/Sistema Económico Latinoamericano, 1999.

CHAKRABARTY, Dipesh. Provincializing Europe. Poscolonial Thought and Historical Difference. Princeton/Oxford, 2000.

CHEAH, Pheng; ROBBINS, Bruce (orgs). Cosmopolitics. Thinking and Feeling Beyond the Nation. Minneapolis: University of Minnesota Press, 1998.

CORRIGAN, Timothy. The Essay Film. From Montaigne, After Marker. Oxford: Oxford University Press, 2011.

CORTÉS, María Lourdes. La pantalla rota. Cien años de cine en Centroamérica. México: Taurus, 2005.

ECHEVERRÍA, Bolívar (comp.). La americanización de la modernidad. Cidade do México: ERA/UNAM, 2008.

FOLICOV, Tamara L. Argentina's Blockbuster Movies and the Politics of Culture under the Neoliberalism, 1989-1998. In: Media, Culture and Society, 22-23, 2000, p. 327-342.

FOUCAULT, Michel. “Outros Espaços”. In: BARROS, Manuel da Motta (org.). Michel Foucault. Estética: Literatura e pintura, música e cinema. Trad. Inês Autran Dourado Barbosa. Rio de Janeiro: Forense, 2009, pp. 411-422.

GETINO, Octavio. Cine iberoamericano. Los desafíos del nuevo siglo. Buenos Aires: Ciccus, 2007.

GRUZINSKI, Serge. La colonización de lo imaginario. Sociedade indígenas y occidentalización en el México español. Siglos XVI-XVIII. México: Fondo de Cultura Económica, 1995 
La guerra de las imágenes. De Cristóbal Colón a "Blade Runner” (1492-2019). Trad. Juan José Utrilla. México: Fondo de Cultura Económica, 2010.

HOBSBAWM, Eric; RANGER, Terence (edts.), The invention of tradition.

Cambridge: Canto, 1992.

HONNETH, Axel. A luta por reconhecimento. A gramática moral dos conflitos sociais. Trad. Luiz Repa. São Paulo: Editora 34, 2003.

JAMESON, Fredric. "Notes on Globalization as a Philosophical Issue". In: JAMESON, Fredric; MIYOSHI, Masao (edts.). The cultures of globalization. Durhan, North Caroline: Dike University Press, 1998, p. 54-80.

KILPP, Suzana. "Manifesto Audiovisualidades". In: SILVA, Alexandre Rocha; ROSSINI, Miriam de Souza (Org.). Do audiovisual às audiovisualidades. Convergência e dispersão das mídias. Porto Alegre: Asterisco, 2009, p. 7-8.

KENWAY, Jane; FAHEY, Johannah. Globalizing the Research Imagination. Nova York: Routledge, 2009.

LOOMBA, Ania et al (edts.). Postcolonial Studies and Beyond. Durham: Duke University Press, 2009.

MANNHEIM, Karl. Ideologia e utopia. Trad. de Sérgio Santeiro. Rio de Janeiro: Editora Zahar, 1976.

MONSIVÁIS, Carlos. “?Cómo se dice OK en inglés? (De la americanización como arcaísmo y novedad). In: ECHEVERRÍA, Bolívar (comp.). La americanización de la modernidad. Cidade do México: ERA/UNAM, 2008, p. 97-120.

NAGIB, Lúcia. “Towards a Positive Definition of World Cinema”. In: Song Hwee Lim e Stephanie Dennison (orgs). Remapping World Cinema: Identity, Culture and Politics in Film. Londres: Wallflower Press, 2005.

ORTIZ, Fernando. Contrapunteo cubano del tabaco y del azúcar. Caracas: Ayacucho, 1978 .

RAMOS, Fernão (org.). Teoria contemporânea do cinema. Pós-estruturalismo e filosofia analítica. São Paulo: Senac, 2005.

(org.). Teoria contemporânea do cinema. Documentário e narratividade ficcional. São Paulo: Senac, 2005.

SORLIN, Pierre. “?Existen los cines nacionales?” In: Secuencias. Revista de historia de cine. Universidad Autónoma de Madrid. N. 7, 1997, p. 33-40.

SUBIRATS, Eduardo. "Las poéticas colonizadas de América Latina". In: ECHEVERRÍA, Bolívar (Comp.). La americanización de la modernidad. Cidade do México: ERA/UNAM, 2008, p. 77-96.

SANTIAGO, Silviano. O cosmopolitismo do pobre. Crítica literária e crítica cultural. Belo Horizonte: UFMG, 2004.

SHAW, Deborah. Contemporary Latin American Cinema. Breaking into the Global Market. Lanham, Maryland: Rowman \& Littlefield Publishers, 2007.

SPIVAK, Gayatri C. Pode o subalterno falar? Trad. Marcos Ferreira Feitosa et al. Belo Horizonte: UFMG, 2010. 
STAM, Robert. Introdução à teoria do cinema. Trad. de Fernando Mascarello. São Paulo: Papirus, 2000.

STEINER, George. Extraterritorial. Ensayos sobre la literatura y la revolución del lenguaje. Trad. de Edgardo Russo. Buenos Aires: Adriana Hidalgo Editora, 2009.

TORTEROLA, Emiliano. "El nuevo cine argentino en la encrucijada actual. Desequilibrios y desafios de la industria cinetográfica nacional”. In: AMATRIAIN, Ignacio. Una década de nuevo cine Argentino. Industria, crítica, formación, estéticas. Buenos Aires: Ciccus, 2009, p. 191-206.

UREÑA, Pedro Enríquez. La utopía en América. La Plata: Estudiantina, 1925.

XAVIER, Ismail. Alegorias do subdesenvolvimento. Cinema Novo, Tropicalismo, Cinema Marginal. São Paulo: Brasiliense, 1993.

YÚDICE, George. La globalización y la nueva división internacional del trabajo cultural. In: LACARRIEU, Mónica; ÁLVAREZ, Marcelo (comps.) La (indi) gestión cultural. Una cartografía de los procesos culturales contemporáneos. Buenos Aires: Ciccus, 2002, p.19-45.

WEBER, Max. Ensaios de sociologia. Rio de Janeiro: Zahar Editores, 1982.

WILLIAMS, Alan (ed.). Film and Nationalism. New Brunswick, Nova Jersey: Rutgers University Press, 2002. 